\title{
Violencia letal en América Latina
}

E. Raúl Zaffaroni*

\section{Resumen}

Tras referirse en forma breve a las corrientes criminológicas que han ocupado el debate durante el último siglo, todas ellas importadas a los países latinoamericanos, el autor advierte sobre la necesidad de cambiar la perspectiva para mirar al norte desde el sur, pues, frente a la situación de -letal- violencia que sufren los países de centro y Suramérica, dichos referentes epistemológicos no brindan ninguna solución. Se hace un llamado a los criminólogos de la región para que orienten sus trabajos al estudio de la realidad local y al escandaloso crimen de genocidio -por goteo- en Latinoamérica, que es ignorado, pese a gestarse a instancia de agencias del Estado o es incentivado por ellas en el contexto de la lucha por el poder.

\section{Palabras clave}

América Latina; criminología; desarrollo, genocidio; genocidio por goteo; masacres estatales; politología criminológica; violencia homicida.

* Ph. D. Profesor emérito de la Universidad de Buenos Aires. 


\title{
Deadly Violence in Latin America
}

\begin{abstract}
After referring briefly to criminological trends that have occupied the debate over the last century, all of them imported to Latin American countries, the author warns of the need to change the perspective to look at north from the south, because facing the -letal- situation of violence suffered by countries in Central and South America, these epistemological references provide no solution. Criminologists of the region are called to direct their work to the study of the local reality and the scandalous crime of genocide - in small doses - in Latin America, which is ignored, despite taking place at the request of state agencies or it is incentivized by them in the context of the struggle for power.
\end{abstract}

\section{Keywords}

Latin America; criminology; development, genocide; genocide in small doses; State massacres; criminological political science; homicidal violence. 


\section{En el curso de un siglo la criminología ha pasado por variados trances o avatares epistemológicos}

La criminología positivista en sentido estricto, propia o cercana al reduccionismo biologista, se consideraba una ciencia autónoma, cuyo eje giraba en torno al hombre delincuente, como sujeto peligroso, inferior y diferente. Su pretensión última era subordinar el derecho penal a la criminología: la misión penal era detectar al hombre peligroso que la criminología le señalaba.

El crepúsculo del paradigma biologista que le servía de base fue precipitado por su manifiesta falsedad científica y por sus gravísimas consecuencias racistas, hasta su crisis total en la Segunda Guerra Mundial.

En Europa y América Latina, el paradigma biologista fue reemplazado por el neokantismo plurifactorial que negaba a la criminología su carácter de ciencia autónoma y la hacía servil del derecho penal, invirtiendo la relación.

La contradicción entre una ciencia natural con límites epistemológicos señalados por una ciencia cultural era resuelta por el neokantismo negando el carácter de ciencia autónoma a la criminología: se la consideraba auxiliar del derecho penal, como una hipótesis de trabajo, nutrida por distintas ciencias.

En los Estados Unidos, la criminología sociológica trató entonces de explicar el delito desde una etiología social. El criminal no nacía, sino que se hacía, y lo hacía la sociedad.

En este marco, la criminología se identificaba con la sociología criminal, en especial con la sociología urbana, pero esa etiología social encerraba una contradicción: la criminología sociológica no tomaba en cuenta el aparato criminalizante, por lo cual seguía sosteniendo una etiología falsa.

La llamada crisis o cambio de paradigma de hace poco más de medio siglo, centró su atención en el ejercicio del poder punitivo, lo que dio lugar a diferentes criminologías (de la reacción social, crítica, radical), con diversas bases teóricas o ideológicas (interaccionismo simbólico, fenomenología, marxismo no institucionalizado, etc.). En definitiva, la aproximó al campo de la ciencia política, o sea que tendía a ser politología criminal. 
Sea como fuere -y más allá de todas sus vertientes y algunas exageraciones-, este giro epistemológico dejó en claro dos puntos: ninguna etiología es válida sin incluir al propio ejercicio del poder punitivo de los estados y, además, es innegable que este siempre es selectivo y se reparte en razón de vulnerabilidad.

Frente a estos puntos firmes de la politología criminal, se ensaya por derecha, como reacción de los diferentes establishments, diversos renacimientos criminológicos, como una vuelta al reduccionismo biologista (mediante la extracción de consecuencias apresuradas de las neurociencias), una criminología administrativa que vuelve al peligrosismo (mediante un pretendido pragmatismo policial preventivo), una criminología economicista (que renuncia a toda etiología, en función de reducción de costos), etc.

Por izquierda, la politología criminal intenta también marchar hacia los daños reales, abarcando todos los daños, especialmente letales, causados por acción u omisión de los estados (medioambientales, discriminatorios, económicos, sanitarios, deteriorantes, etc.), con lo cual la criminología pasaría a ser una suerte de campo casi ilimitado de dañología política.

\section{Todos estos avatares epistemológicos los importamos a América Latina desde el hemisferio norte y los deglutimos en mayor o menor medida en cada momento histórico, al tiempo que hicimos muy poca investigación criminológica de campo}

Ha llegado al momento de mirar al norte desde el sur. No se trata de ninguna elección arbitraria, ni de ninguna declaración de independencia científica nacionalista, sino que nos enfrentamos a una brutal realidad, a una acuciante necesidad, que son las muertes, la letalidad violenta que recorre nuestra región.

Frente a la horrorosa violencia en Latinoamérica, los avatares epistemológicos del norte no nos brindan ninguna explicación y menos aún, alguna solución. Ninguna de esas criminologías del norte nos permite enfrentar la letalidad violenta de nuestra región.

Pero al mirarlas desde el sur, salta hoy a nuestra vista de marginales planetarios australes una omisión terrible de las criminologías del norte: estudiaron todos los fenómenos criminales o, mejor dicho, casi todos, porque hay uno, que no solo cometieron sus propios estados en tierras lejanas, sino que también padecieron en carne propia, que es el peor de todos los crímenes, y que, pese 
a su innegable visibilidad, dejaron cuidadosa y sospechosamente fuera de sus límites epistemológicos: ninguna de esas criminologías se ocupó del genocidio.

El genocidio fue materia de historiadores, politólogos, sociólogos, antropólogos, filósofos, etc., pero no de criminólogos. El raquitismo de la producción criminológica acerca del genocidio es notorio y ha sido destacado en los últimos años.

Esta crítica desde la mirada austral nos la impone hoy un brutal dato de la realidad, claramente puesto de manifiesto por las investigaciones de Elías Carranza: de los 23 países que, según cifras oficiales, registran tasas de homicidio superiores a 20 por $100 \mathrm{mil}$ anuales, 18 se hallan en América Latina y el Caribe y 5 en África.

Si sumamos las víctimas de los homicidios cometidos en la región en una década, veremos que acabamos con una ciudad de respetables dimensiones. Tenemos en curso, pues, unas Hiroshimas y Nagasakis con paciencia. Por acción u omisión, nuestros propios estados son nuestras Fat men y Little boys, lanzadas contra nosotros mismos o, mejor dicho, contra nuestras clases subalternas y nuestros disidentes, por acción u omisión de nuestras propias agencias vernáculas.

Esto también es genocidio. La extensión temporal del genocidio no le quita su sentido de masacre política y estatal. La baja intensidad continuada en el tiempo no cancela el concepto: se trata de un genocidio por goteo, pero genocidio al fin. La masacre es tal aunque se cometa de a poco y con paciencia.

Este -y no otro- debe ser el tema central de nuestra criminología en el momento presente de nuestra región, si es que no queremos distraernos estudiando casos patológicos menores y escapándonos de nuestras realidades.

La letalidad es nuestro problema central. Nuestros muertos son la cuestión actual. Y no tenemos respuestas desde el norte. Es nuestro deber como científicos, como criminólogos, como estudiosos, centrar nuestra atención en la letalidad violenta de nuestra región. De no hacerlo, actuaríamos como si la ciencia médica se ocupase por entero del estudio de enfermedades exóticas en medio de una epidemia de tifus.

A continuación, nos ocupamos, pues, de la urgente necesidad de mirarnos a nosotros mismos desde nuestra posición en el mundo, desde nuestra perspectiva austral. 
Los genocidios o masacres estatales, a la largo de toda la historia, han sido cometidos por agencias del poder punitivo o incentivados por ellas (Gestapo, KGB, etc.). Incluso cuando los cometieron fuerzas militares, no lo hicieron en función bélica, sino punitiva o directamente policial

Justamente por eso es que se trata del crimen más escandaloso, porque superpone e identifica el poder punitivo con el poder criminal. El poder presumiblemente preventivo del crimen se vuelve criminal, lo que provoca la anomia más radical: no hay normas, porque al amparo de la norma destinada a tutelar la vida, se comete el crimen masivo contra la vida.

Por otra parte, ningún genocidio se comete porque sí, sino que todos los genocidios, desde el de Cartago hasta el de Sudán, pasando por los del colonialismo en América y África, por el armenio, por la Shoá, el camboyano, el de Ruanda, etc., responden siempre a una lucha de poder.

Obviamente, el actual genocidio por goteo que sufrimos en la región también tiene lugar en un contexto de lucha de poder que, en este mundo globalizado, es una lucha de poder planetario.

Si no tenemos claro cuál es este contexto y qué papel nos incumbe en él, no podremos comprender qué nos está pasando.

Es menester, sin embargo, una advertencia previa, sobre el poder mismo.

Las explicaciones acerca del poder pueden llevar a pensar con frecuencia en conspiraciones o, al menos, en una serie de acciones planificadas fríamente e instrumentadas del mismo modo, cuando en realidad el poder no funciona de esa forma. En la dinámica del poder, se producen fenómenos que son disfuncionales o funcionales a ciertos intereses. Por lo general, el poder consiste en contener o neutralizar los disfuncionales y favorecer o dejar correr los funcionales.

Si no partimos de esta idea, corremos el riesgo de acabar creyendo que todo es producto de una máquina inteligente poco menos que inmodificable, lo que nos puede llevar a la desesperación y con frecuencia a lo irracional. Ni tan inteligente es el poder, ni tampoco tan inmodificable: su propia dinámica permite verificarlo. 


\section{¿Cuál es el actual contexto de lucha de poder mundial y cuál la posición de nuestra región?}

Vivimos en un mundo polarizado, en el que ya la contradicción no se da entre un llamado socialismo real, que pretende la socialización de los medios de producción (para acabar en una elitización burocrática opresiva), y un capitalismo que se presenta como garante de tolerancia y liberalismo político, sino que la contradicción polarizante tiene lugar dentro del mismo capitalismo.

En efecto, la actual polarización está dada entre un capitalismo productivo más o menos razonable y un capitalismo financiero transnacional que cada vez concentra más riqueza en menos manos.

Sin entrar en mayores detalles, según el informe de Oxfam y los datos del Credit Suisse, el año pasado el 1\% de la población mundial era dueña del $48 \%$ de la riqueza del mundo, tendencia que se acentúa desde 2010 y que de seguir el mismo curso, llegará al 54\% en 2019.

Pero solo una quinta parte del $99 \%$ restante de la población mundial concentra la mitad del 52\% que le queda, con clara tendencia a subir.

A estos polos corresponden dos modelos de Estado, que procuran configurar dos diferentes modelos de sociedad: el que va en pos de una sociedad más o menos distributiva y con tendencia incluyente, y el que procura una sociedad llamada de 30 y 70 (30\% de incluidos y $70 \%$ de excluidos).

El primero sería el modelo del Estado de bienestar o welfare State y el segundo el del Estado gendarme (o guardia nocturno), cuya única función sería la de garantizar la libertad de mercado.

El primero estaría más o menos asentado sobre base keynesiana o neokeynesiana y el segundo sobre la idolátrica omnipotencia de mercado de Friedman y von Hayek.

El primero sería el modelo del New Deal de Roosevelt y el segundo el de Reagan, Bush y Tatcher.

Al giro de un modelo a otro, producido a partir de la crisis del petróleo de los años setenta, corresponde la hipertrofia del poder punitivo norteamericano, estudiada en detalle por el profesor de criminología de California, Jonathan Simon. 


\section{En este contexto mundial estamos. Ocupamos un lugar periférico del poder planetario, como lo hacemos desde hace cinco siglos}

Habíamos sufrido una etapa originaria de colonialismo que terminó con la independencia formal y que correspondió al poder planetario surgido de la revolución mercantil (siglo XV).

Luego hubo otra etapa, el neocolonialismo, que se valió de oligarquías locales (porfirismo mexicano, oligarquía vacuna argentina, república velha brasileña, patriciado peruano, etc.), que correspondió al poder planetario generado a partir de la Revolución Industrial (siglo XVIII) y que llegó a su término con las dictaduras de seguridad nacional del sur, en la segunda mitad del siglo pasado.

Ahora vivimos la fase superior o avanzada del colonialismo, que corresponde al poder mundial que se genera a partir de la revolución tecnológica (fines del siglo XX).

El poder financiero transnacional, agente activo de esta fase superior del colonialismo, nos quiere configurar como sociedades excluyentes $y$, por ende, se esfuerza por imponernos estados que las configuren.

La sociedad 30 y 70 necesita, inevitablemente, controlar socialmente al $70 \%$ de los excluidos.

Hasta hace algunas décadas hubiésemos creído que ese control se llevaría a cabo solo por medio de la fuerza, o sea, de un Estado que montase agencias policiales genocidas. Por decirlo de alguna manera, aún hoy, especialmente en los partidos y fuerzas de izquierda tradicional, hay quienes no caen en la cuenta y creen que en esta fase avanzada, la exclusión también será controlada por los cosacos del zar.

Pero ya no hay cosacos ni zares, y tampoco son las agencias del poder punitivo del Estado las que producen el mayor número de muertes, por mucho que haya letalidad policial en la región, que por cierto no falta.

El control social de la exclusión, en esta fase avanzada del colonialismo, no se ejerce principalmente mediante la letalidad policial, sino de una manera mucho más sofisticada, montado sobre procesos que se han ido dando y que el propio colonialismo fomenta.

La clave del control letal está en el fomento de las contradicciones y conflictos entre los propios sectores excluidos y, como máximo, entre éstos y la faja más baja incorporada a la clase media inferior. 
La selectividad punitiva no solo opera en la criminalización, sino también en la victimización y en la policización. Víctimas, victimarios y policizados pertenecen a estos sectores en toda la región.

Estos procesos son perfectamente funcionales al modelo de sociedad excluyente: en la medida en que los excluidos se maten entre ellos, la violencia les impide tomar consciencia y coaligarse y, por tanto, tener un protagonismo político coherente conforme a sus intereses.

Además, de esa manera, se disminuye un poco el número de excluidos, es decir, de descartables. Tengamos en cuenta que el excluido no es el explotado de otros tiempos, necesario al explotador. El excluido no es necesario para nadie, está de más, es un estorbo, una molestia, algo no solo prescindible, sino indeseable como presencia. Molesta al mercado y no aporta nada en ese esquema de teocracia de mercado. No hay dialéctica entre exclusión e inclusión, hay solo un mutante que sobra.

En este mundo que concentra riqueza aceleradamente, motorizado porel capital financiero a través delas corporaciones transnacionales (y amparado por organismos económicos supranacionales), en pugna con una producción capitalista razonable, los procesos de concentración favorecen los monopolios y los oligopolios en todos los órdenes

La ideología de este proceso se basa en la llamada teoría del derrame, según la cual nada debe obstaculizar la concentración de riqueza, puesto que esta producirá en un momento el derrame hacia abajo.

Para eso es necesario mantener los sistemas tributarios regresivos en la región (con predominio de impuestos al consumo) y no obstaculizar la formación de monopolios y oligopolios.

Cabe observar que esta era la ideología de la jurisprudencia norteamericana de la segunda mitad del siglo XIX, o sea, que se trata de un retroceso ideológico de un siglo y medio.

La historia demuestra, además, que nunca se derrama nada si alguien no empuja un poco la copa.

En este fenómeno, cobra particular importancia la oligopolización de los medios masivos de comunicación social, en particular de la televisión, que es la mayor fuente de creación de realidad en nuestra región. 
México, Brasil, Argentina, etc., tienen su televisión oligopolizada o monopolizada, es decir, que no solo existe un discurso único, sino también una única creación de realidad mediática en nuestros países.

Desde Roosevelt por el lado bueno y Hitler por el malo, todos sabemos la importancia de los medios de comunicación en la política y en la creación mediática de la realidad, en términos de lo que desde la fenomenología pusieron de manifiesto hace muchos años Berger y Luckmann, y que hoy son de elemental manejo en cualquier carrera de comunicación social.

Tampoco es necesario recordar aquí los tristísimos resultados del discurso y la creación de realidad únicos, tanto en el período de entreguerras como con posterioridad a este.

Nuestros medios masivos monopolizados no están al servicio del capital financiero transnacional, sino que son parte de este, en razón de su volumen económico y de los múltiples vínculos con los que se entrelazan indisolublemente.

Por consiguiente, nuestras sociedades perciben la realidad de la violencia a través de la creación de los medios, que la minimizan o la maximizan, según las circunstancias locales y la diferente forma de promover el control de la exclusión social.

Esta pendulación se observa claramente en la región: en los países donde la violencia es alta, la neutralización de los excluidos se produce por efecto de la violencia misma y, por ende, es funcional al capital financiero y a su programa de exclusión. Allí los medios monopólicos la minimizan o la naturalizan. En los pocos países en que la violencia es relativamente menor y, por ende, no alcanza ni es ninguna garantía de contención de la exclusión, la maximizan exigiendo el montaje de un aparato represivo muy fuerte, con el que creen que lograrán ese control.

\section{La sociedad excluyente es, por definición, una sociedad en que domina la desigualdad, o sea, en que la distribución de la riqueza es injusta hasta límites indignantes}

Esta es la principal característica del modelo preferido del capital financiero transnacional y sus corporaciones, como también de los medios monopolizados, que forman parte de estas. 
No en vano América Latina es -como bien lo observa Carranzacampeona de dos índices: el señalado de homicidios y, además, de los coeficientes de Gini, o sea, de los indicadores de distribución de riqueza que muestran una región con altísima disparidad o injusticia social.

Conforme a la experiencia mundial, a mayor PIB hay menos homicidios, es decir, que se trata de dos curvas que se cruzan, pero no siempre simétricamente, porque incide sobre esta regla el coeficiente de Gini, o sea, la disparidad en la distribución de la renta.

Muchas veces se ha dicho que no es la pobreza lo que produce delito en forma inexorable, en principio porque el delito atraviesa todas las capas sociales (lo sabemos desde Sutherland), pero también porque hay circunstancias de extrema necesidad que no dan lugar a violencia (terremotos, catástrofes, etc.), porque la situación dramática y la urgencia por superarla, refuerzan el sentimiento de comunidad y pertenencia (el proyecto común). Lo que produce delito es la pobreza sin esperanza, o sea, la frustración, la sociedad sin movilidad vertical que no permite proyecto, cuando la existencia humana misma es proyecto. Esto es lo que explica la correlación entre homicidios y coeficiente de Gini.

Lo anterior debe llevarnos a la conclusión de que el derecho humano más lesionado en la región es el que los autores de los países centrales consideran de tercera generación, que es el derecho humano al desarrollo.

Desde la perspectiva austral de países colonizados, este es el primer derecho humano, porque la primera condición del desarrollo es la independencia. Nuestros primeros luchadores por los derechos humanos fueron, por tanto, los héroes de nuestras independencias.

En modo alguno con esta afirmación pretendemos negar la realidad de la lesión masiva al derecho humano a la vida, sino todo lo contrario: es la violación al derecho humano al desarrollo lo que produce la letalidad. Es la mala distribución de la riqueza que produce muertos. El que mata es el colonialismo en todas sus etapas, porque su esencia radica en la negación del derecho humano al desarrollo.

No cabe en este breve espacio mostrar la terrible letalidad del colonialismo genocida en África, cuidadosamente ocultada por los medios de comunicación oligopólicos, pero es altamente recomendable-por si no nos alcanza con nuestra propia experiencia-, 
que los latinoamericanos echemos un atento vistazo a la historia del último siglo del continente olvidado.

Cuando hablamos de la letalidad de la negación del derecho humano al desarrollo (o del colonialismo) no podemos dejar de observar que solo estamos contando los muertos por violencia homicida, pero si a éstos sumásemos todos los muertos por efectos de la lesión al derecho al desarrollo humano, quedaríamos aún más espantados: suicidios conscientes e inconscientes, víctimas de la selectividad en el servicio de salud (en especial niños y ancianos), de subalimentación, de tránsito por insuficiente o inadecuada red vial, de desplazamientos forzados de población.

Si pudiésemos medir todo ese conjunto, sin duda podríamos afirmar que la violación al derecho humano al desarrollo, fomentada hoy al extremo por el capital financiero transnacional, es la causa de un genocidio que deja de ser por goteo para pasar a ser directamente a chorros.

La distribución de la violencia en el mapa de la región indica diferencias considerables, en particular en la forma en que contrastan los índices de casi toda la región con los de los tres países más australes (Uruguay, Chile y Argentina). Brasil, por ejemplo, cuadruplica y hasta quintuplica los índices de estos tres países

La altísima violencia que condiciona el genocidio por goteo que sufre casi toda la región, al igual que esta diferencia con el Cono Sur, no podrían explicarse sin la incidencia de la economía creada por la prohibición de la cocaína, como de otros tóxicos con menor incidencia.

La demanda de este tóxico no solo es rígida, sino que se fomenta mediante una publicidad paradojal, que asocia su uso a la transgresión, siempre atractiva a las capas jóvenes.

Ante esta demanda incentivada, la prohibición reduce la oferta y provoca una formidable plusvalía del servicio de distribución, que se controla mediante las agencias que persiguen el tráfico y que desempeñan la función económica de entes reguladores del precio de la cocaína.

Se trata de un rudimentario recurso alquímico, que bien podría usarse con cualquier otro objeto, por despreciable que fuere, siempre que tuviese una demanda rígida o en condiciones de ser aumentada. 
El tóxico se produce en nuestra región. La competencia por alcanzar el mayor mercado de consumo (la exportación a los Estados Unidos), tiene lugar también en América Latina, con altísimo nivel de violencia competitiva en los países más próximos. No obstante, más de la mitad de la renta de este negocio (eufemísticamente llamado crimen organizado) queda en la red que presta el servicio de distribución interno en los Estados Unidos. Por otra parte, desde ese país se exportan armas a las bandas que compiten en el sur, al tiempo que sus bancos se reservan el monopolio del reciclaje de dinero de la totalidad de la renta.

Esta es la diferencia fundamental con la prohibición alcohólica de los locos años veinte del siglo pasado. En ese caso, la producción, la competencia para alcanzar al consumidor y la distribución se hacía en el interior del territorio norteamericano, lo que dio lugar a la simbiosis de crimen violento y astuto, usualmente conocida como mafias. En su lugar, hoy rige una clara división internacional del trabajo en materia de cocaína, donde la peor parte queda al sur del Río Bravo: México se queda con los muertos y Estados Unidos con la mayor parte de la renta.

Para garantizar el monopolio del reciclaje en el norte, existe un organismo internacional secundario -el GAFI-, que abusa de $\mathrm{su}$ autoridad extorsionando con graves sanciones económicas a nuestros países, con el pretexto de controlar el financiamiento del terrorismo, al tiempo que los obliga a tipificar penalmente esta figura difusa, abriendo la posibilidad de su utilización para la criminalización de disidentes y minorías, como ha sucedido con los indios mapuche en Chile.

La prohibición de la cocaína también genera mercados internos en nuestros países, lo que da lugar a un tráfico que en buena medida es de supervivencia, al menos en sus eslabones menores. También este tráfico interno provoca letal competencia violenta en las zonas más humildes, sobre las que opera una considerable intervención policial, puesto que inevitablemente la cobertura de algún grupo en perjuicio de otros, pasa a ser una fuente de recaudación de alto valor para las cúpulas de las agencias policiales autonomizadas.

La guerra a la droga que, como era previsible, estaba perdida desde el comienzo, ha desencadenado la mayor parte de la letalidad violenta de la región. Ha causado muchos miles de muertes de jóvenes en pocos años, cuando se hubiesen necesitado siglos para provocar un número cercano por efecto del abuso del tóxico. 
En América Latina hoy la cocaína no mata por sobredosis, sino que el problema de salud lo provoca ahora su prohibición, que da por resultado muertes por concentración aguda de plomo. Desde el punto de vista sanitario se convierte en una causa de muerte importante, en particular en la faja joven.

Tampoco es verdad que haya una alta incidencia de homicidas intoxicados por cocaína. Infinitamente mayor en toda la región es el número de homicidios cometidos bajo efectos del alcohol, que sigue siendo nuestro tóxico criminógeno por excelencia.

Esta política suicida y absurda desde el punto de vista penal y sanitario, solo es coherente como instrumento colonialista para corromper a las instituciones policiales, para infiltrarse en la política $\mathrm{y}$, en algunos países, para desprestigiar a las fuerzas armadas y debilitar la defensa nacional.

\section{Llego al punto más delicado de esta exposición ante criminólogos mexicanos}

Quiero aclarar que no desempeño ninguna función oficial en mi país, o sea, que lo que diga es exclusivamente mi opinión personal y no compromete en nada al gobierno argentino.

Sería sumamente grave que en este encuentro pasásemos por alto que hoy México es la peor víctima de este genocidio por goteo, que ya también lo está padeciendo a chorros.

La causa es de toda evidencia, no solo para los criminólogos, sino incluso para los políticos. Lo ha dicho aquí Bill Clinton hace unas semanas: el reforzamiento de los controles del acceso de cocaína por vía marítima y aérea a los Estados Unidos, ha intensificado la vía terrestre que pasa por Centroamérica y México.

Por otra parte, todo indica que en México, el pretendido giro hacia la guerra total a la droga fue determinante para el salto en la cifra de muertes violentas.

Hay también víctimas menores, como Honduras, donde el índice de homicidio de San Pedro Sula es el más alto del mundo $(80 \mathrm{x}$ 100.000).

Por otra parte, también se produce un alivio en la violencia colombiana, como resultado de este desplazamiento. 
Por las noticias que trascienden, en México todo pareciera reducirse a una lucha de cifras, a una suerte de contabilidad mortal muy particular. Si oficialmente se reportan 15.646 muertos en 2014, Amnesty cuenta 24.746. El servicio de personas desaparecidas, de todos modos, parece registrar 13 personas diarias en los últimos años.

Más allá de esta disputa, que sin duda tiene efectos políticos internos y coyunturales que no deben interesarnos aquí, desde la perspectiva criminológica esta lucha de números entre los datos oficiales mexicanos y los reportados por organizaciones no gubernamentales, no son ninguna clave decisiva, porque incluso los datos oficiales son demostrativos de un alto grado de descontrol de la violencia.

En tanto no haya una clara muestra de descenso del nivel de muertes y desapariciones, la interpretación de las tendencias no significativas son manipulables en cualquier sentido, de modo que desde la observación criminológica no indican que el fenómeno vaya decididamente por el camino de la contención y reversión.

La tesis de la meseta, según la cual se habría estabilizado y, por ende, cesado de aumentar, no es tampoco tranquilizadora. Más bien es una tesis naturalizante o normalizadora de la violencia letal.

Por lo que vemos en los medios masivos de comunicación mexicanos, creemos que, dado que no pueden negar la alta violencia letal, se inclinan por todo lo que sea naturalizante y normalizador.

Se le está creando al público mexicano una realidad, según la cual, la violencia letal viene de algún lado desconocido, se ha desatado como un fenómeno poco menos que natural con el que es menester convivir.

Esta creación de realidad mediática normalizadora, no solo es falsa, porque oculta la clara raíz de la mayor parte de la violencia, sino que es infamante para el pueblo y la nación mexicana.

La televisión monopólica mexicana no es tan tonta como para decirlo expresamente, pero deja flotando en el aire la hipótesis de que esta violencia sería producto de una supuesta personalidad básica violenta del pueblo mexicano, que sería ratificada por la historia y hasta por la antropología, lo que, fuera de cualquier duda, no es más que una verdadera infamia racista. 
La violencia de la historia mexicana -creo no tener necesidad de recordarlo aquí-, todos sabemos que no parte de México, sino que es el producto de las agresiones colonialistas y neocolonialistas que ha sufrido México a lo largo de los últimos cinco siglos. La infamia descalificante, en modo alguno la confirma la historia, sino todo lo contrario.

No es posible aceptar este insulto al pueblo de México, que las tesis naturalistas dejan entrever, porque está lesionando la autoestima de un pueblo y la perversa y distorsionada interpretación de sus sufrimientos seculares.

Lo que queda flotando -sugerido por la naturalización mediática de la violencia- es un retorno a los tiempos de Bulnes o de las tesis del grupo de los científicos del Porfiriato.

Debe observarse que este es el mismo racismo que, en forma apenas más sutil que hace un siglo, se difunde por los medios de comunicación del capital financiero transnacional para naturalizar la violencia letal en África, que según ellos obedecería a primitivismo, pero que calla meticulosamente los intereses en la venta de armas, en la expoliación de las riquezas minerales, en el agotamiento del suelo por explotación irracional, en el mantenimiento de hecho del apartheid, etc.

Queridos colegas: no hablo desde la soberbia argentina. Soy consciente de que si en mi país no tenemos esta violencia, no se debe a que seamos mejores que ustedes, sino a nuestra posición geopolítica, que coyunturalmente nos saca de la producción y de la ruta internacional del tóxico prohibido.

Hablo, además, desde el conocimiento y el afecto que me une a esta mi segunda patria y que me enseñaron mis maestros mexicanos hace medio siglo, como Quiroz Cuarón y Porte Petit, entre otros.

No deben ustedes, en modo alguno, aceptar la normalización de esta violencia, porque importa una gravísima injuria al pueblo mexicano, a su historia, a su tradición, importa el regreso al más descarnado racismo del neocolonialismo, a las ideologías spencerianas propias de nuestras repúblicas oligárquicas, cuya crisis comenzó precisamente con la Revolución Mexicana hace más de un siglo, y que le costó a México la guerra civil más dolorosa de la centuria pasada. 
Es vuestra historia y son vuestros muertos los que están siendo burlados con la tesis de la normalización de la violencia. Aquí no hay nada normal, sino un claro condicionamiento político internacional, una división internacional del trabajo en que hoy a México le toca llevar la peor parte.

\section{Los medios masivos de comunicación del extranjero que responden al capital financiero transnacional, agitan el fantasma de México: cuidado que nos puede pasar lo mismo}

Es obvio que nos puede pasar lo mismo, pero siempre y cuando el capital financiero nos haga lo mismo que le hace a México y saque ventaja con los mismos negocios inconfesables, como su monopolización del reciclaje del dinero sucio. Esto último es lo que no nos dicen en el extranjero.

En mi país, como hemos dicho, dado que nuestros excluidos son poco aficionados a matarse entre ellos, los medios monopolizados crean mediáticamente una violencia mayor, para promover la sanción de leyes absurdamente autoritarias, para favorecer la autonomización de nuestras policías, para crear un aparato represivo de control de la exclusión social. Para eso nos agitan el fantasma de México, pero no nos dicen a qué se debe, lo ocultan celosamente, como no puede ser de otro modo, porque se debe a lo que esos mismos intereses hacen aquí, donde el discurso mediático es de normalización y calma.

Aquí el discurso es que los muertos y los desaparecidos y los secuestros ya no aumentan, que Ayotzinapa y otros episodios son casi municipales, que las desapariciones son homicidios $\mathrm{y}$, en el fondo, sin decirlo muy claramente, que todo responde a que el mexicano es violento.

Vale decir, que hay una nota de inferioridad que requiere un paternalismo contenedor, igual que en tiempos de Porfirio Díaz.

Se ha hablado de un Estado fallido en México. Depende de qué se entienda por tal, pero a mi juicio esto no es verdad. Entiendo por Estado fallido el fenómeno que tiene lugar cuando una nación es débil y no logra constituir un Estado, como sucedió en algunos países -en especial en África- después de su independencia formal del neocolonialismo.

En modo alguno es este el caso de México, donde la nación es fortísima, quizá con el sentimiento de comunidad nacional más 
fuerte de toda nuestra región y donde, además, se llegó a configurar un Estado que, en ocasiones, debemos reconocer que fue demasiado Estado, o sea, todo lo contrario de fallido.

Aquí hay algo por completo diferente: se trata de un Estado acosado por el colonialismo propio de esta fase avanzada. Se trata de un estado debilitado y carcomido desde algunas de sus bases mismas por la acción del colonialismo, que hoy adopta estas formas de ejercicio del poder hegemónico.

Es posible que existan falencias en la defensa frente a esta agresión del colonialismo, que incluso puede tratarse una verdadera agresión desde el punto de vista del derecho internacional. Esta es una cuestión que incumbe a la política interna de México, en la que no tomamos partido, pero cualquiera sea la opinión, no pueden nunca confundirse las falencias en la defensa con la causalidad desatada por la agresión misma. Una agresión sigue siendo tal aunque el agredido se defienda mal o incluso no se defienda.

\section{De lo expuesto hasta aquí debemos extraer algunas conclusiones}

En primer lugar, debemos reflexionar acerca de nuestro propio saber. La criminología no puede ignorar a la política, porque cada día más es un saber político o, al menos, no puede ignorar su parte de politología criminológica, pues aceleradamente los hechos la aproximan más a la ciencia política que a la propia sociología. Quedan muy atrás los reduccionismos arqueológicos de nuestro saber, que intentan resucitar quienes en la criminología manipulan a favor de los intereses colonialistas.

Tenemos ante nuestros ojos un fenómeno de altísima violencia, como claro producto de la política internacional. No podemos en Latinoamérica seguir a la zaga del saber criminológico central, que ignoró el genocidio o la violencia letal por acción u omisión estatal, porque tenemos un genocidio en marcha ante nuestra vista.

Nuestro saber debe encarar seriamente su estrecho vínculo con el saber político. Es urgente convocar politólogos para nuestros análisis.

En cuanto a la principal fuente de violencia genocida en la región, es decir, a la lesión del derecho humano al desarrollo, es claro que el camino particular que cada Estado escoja para superarlo, es una 
cuestión decididamente política de cada país, pero nuestro deber es señalar la infracción y la necesidad de discutirlo políticamente para identificar las vías más idóneas.

En lo que hace al problema puntual de la prohibición de cocaína, no hay soluciones simplistas.

No nos animamos a afirmar que la solución sería la inmediata legalización del tóxico problemático, que acabaría abruptamente con la plusvalía del servicio de distribución. Al respecto, dado el fabuloso volumen dinerario alcanzado, ignoramos las consecuencias económicas de una medida de esta naturaleza: no sabemos qué efectos puede producir en las economías de varios países de la región, tampoco qué sucedería con la mano de obra empleada hoy para la producción y distribución del tóxico.

Tampoco sabemos qué función cumple la inyección de dinero en el circulante mundial, proveniente de esta artificial plusvalía del servicio de distribución. De cualquier manera, no deja de llamar nuestra atención el entusiasmo por la legalización por parte de algunos líderes de la idolatría del mercado. Posiblemente, estén entreviendo cierta disfuncionalidad del negocio.

Obviamente que estos son problemas propios de los especialistas en macroeconomía, cuyo auxilio necesitamos con urgencia.

En el plano de la política internacional, sería bastante urgente que se le exigiese a los Estados Unidos que desmonte su red interna de distribución y, además, que deje de vender armas al sur y de reciclar dinero.

Difícil es que se tomen estas medidas, sabemos de la inmensa dificultad política internacional, no somosingenuos. También sabemos que aunque la administración norteamericana se lo propusiese, chocaría con fortísimas resistencias de sus propias agencias y de los políticos alineados con el capital financiero transnacional.

Pero, de todos modos, debemos decirlo, porque quien está en un pozo, antes que nada, debe tomar consciencia de que está en un pozo, para después ver cómo puede salir de él.

Queridos colegas: no se sale fácilmente del colonialismo después de cinco siglos. Pero lo primero que debemos hacer es reconocer que estamos bajo los efectos del colonialismo, solo que en una fase 
superior de este. Y la criminología no puede ignorar este fenómeno del poder regional y mundial, porque estaría negando lo que la realidad nos pone todos los días delante de nuestros ojos.

Disculpen si les he hablado con extrema sinceridad, pero he sentido la necesidad de hacerlo. Achebe, un conocido poeta nigeriano, ha escrito que la historia se ha contado del lado del cazador y no del león. Así como es necesario contarla desde el lado del león, también debemos hacer criminología desde ese lado. En este sentido, como latinoamericano y por el amor y el inmenso agradecimiento que le debo a México, pero también por la dignidad y el prestigio de la propia criminología. 